\title{
Distribution patterns of European lacustrine gastropods: a result of environmental factors and deglaciation history
}

\author{
Elisavet Georgopoulou - Thomas A. Neubauer • \\ Mathias Harzhauser · Andreas Kroh · Oleg Mandic
}

Received: 2 December 2015/Revised: 18 February 2016/ Accepted: 20 February 2016/Published online: 1 March 2016

(C) The Author(s) 2016. This article is published with open access at Springerlink.com

\begin{abstract}
Contemporary climate and deglaciation history have received strong support as drivers of species richness and composition for several European taxa. We explored the influence of these factors on patterns of species richness and faunal composition of 244 freshwater gastropod species from 898 European lakes. We evaluated the influence of late Pleistocene deglaciation and seven physiographical and climatic factors on gastropod distributions using multiple linear regression models. We investigated species beta diversity patterns and the influence of species dispersal abilities and/or environment on species composition between lake subsets with different deglaciation history. Contemporary factors and deglaciation history explain parts of variation in species richness across European lakes. Beta diversity analysis revealed moderate to high differences in species composition between the predefined groups. Patterns of species replacement and species loss indicate that lacustrine gastropod faunas of formerly glaciated
\end{abstract}

Electronic supplementary material The online version of this article (doi:10.1007/s10750-016-2713-y) contains supplementary material, which is available to authorized users.

Handling editor: Koen Martens

E. Georgopoulou $(\bowtie) \cdot$ T. A. Neubauer .

M. Harzhauser · A. Kroh · O. Mandic

Geological-Paleontological Department, Natural History

Museum Vienna, Burgring 7, 1010 Vienna, Austria

e-mail: elisavet.georgopoulou@nhm-wien.ac.at areas are subsets of non-glaciated ones. Dispersal limitations and environmental gradients control patterns of beta diversity within different lake subsets. We find strong support that the distribution of European limnic gastropods, at least partially, carries the imprint of the last Ice Age. The differences in species richness and composition point towards a gradual, ongoing process of species recolonization after deglaciation.

Keywords Freshwater snails - Species richness · Beta diversity · Ice Age effects · Contemporary predictors

\section{Introduction}

What shapes species richness over large geographical scales? This question has been addressed by a plethora of scientific works over the years testing a number of potential hypotheses (see Rahbek \& Graves, 2001). Current environmental conditions are usually addressed as the primary determinant of broad-scale species richness patterns (e.g., Hawkins et al., 2003). Lately, the importance of historical events as a driving force in shaping spatial patterns of species distribution has received considerable attention (e.g., Hewitt, 1999, 2000; Graham et al., 2006; Araújo et al., 2008). Variations in glacial history of Europe have affected patterns of post-glacial recolonization in a 
range of species, with examples from beetles (Fattorini \& Ulrich, 2012; Ulrich \& Fattorini, 2013), fish (Reyjol et al., 2007), plants (Normand et al., 2011), mammals (Fløjgaard et al., 2011), reptiles and amphibians (Araújo et al., 2008). Species ecological traits along with climate and historical events have shaped the present-day latitudinal richness gradients of several European taxa (e.g., Hof et al., 2008; Fattorini \& Ulrich, 2012). In particular, the relationship of European freshwater species richness in lentic habitats (i.e., standing waters including lakes) with latitude is apparently related to species dispersal abilities (Hof et al., 2008).

Freshwater gastropods have received considerably less attention than other taxa, although they represent a rich clade with several hundred species described for Europe (de Jong, 2012). Only few studies have been carried out for few terrestrial (e.g., Harl et al., 2014) and freshwater (e.g., Cordellier \& Pfenninger, 2008, 2009; Benke et al., 2011) gastropod taxa. The phylogeography and ecological niche modelling of Radix balthica (Linnaeus, 1758) revealed at least two cryptic refugia in north-western Europe during the late Pleistocene glaciations, while the species later expanded its range by tracking suitable habitats (Cordellier \& Pfenninger, 2009). A similar methodological approach showed that Ancylus fluviatilis Müller, 1774 occupied northern European refugia and expanded its postglacial range by adapting to the warming conditions (Cordellier \& Pfenninger, 2008). Other works addressed regional biogeographical (e.g., Radoman, 1985; Økland, 1990) and phylogeographical relationships in lake and spring gastropods (e.g., Wilke et al., 2007; Benke et al., 2011). Økland (1990) recorded only 27 gastropod species from over 1,000 Norwegian lakes, identifying that variation in species richness depends largely on lake characteristics, climate, historical immigration routes and topography. Apart from that, research often focused on the rich and highly endemic faunas of the ancient lakes of the Balkan Peninsula and Asia Minor (e.g., Albrecht et al. 2006; Wilke et al., 2007). Although the abovementioned studies on European freshwater gastropods allow for discerning differences in species distribution and/or ecological adaptations, the biogeographical affinities of panEuropean lacustrine gastropods are still poorly understood and a comprehensive approach is lacking.

European lakes cover a wide climatic, altitudinal and historical range. Lakes in Scandinavia and the
Alpine region are geologically young, mostly of postPleistocene origin, formed after the retreat of the glaciers following the Last Glacial Maximum (LGM, c. 20,000 years BP). In large parts of Scandinavia, the ice sheet started to retreat not before the onset of the Holocene (corresponding to the end of the Younger Dryas [YD], c. 11,000 years BP). On the contrary, south-eastern Europe is hotspot for long-lived lakes, some of which date back to the late Pleistocene and before (e.g., Lake Ohrid; Wagner et al., 2014b). The Iberian and Balkan Peninsulas, Italy and Asia Minor were hardly coved by ice at all, with the exception of the Pyrenees and a few restricted areas in the southeast (see Ehlers et al., 2011 for a detailed map). Naturally, in such a broad geographical range we would expect the distribution of lacustrine gastropods to reflect adaptations to different climatic regimes and hydrological characteristics.

The present study, for the first time, explores broadscale drivers of gastropod distribution in European lakes by addressing three main hypotheses. (1) Gastropod species richness across European lakes can be explained by physiographical and climatic factors. Considering previous studies, we expect a relation of species richness with latitude which may be driven by climatic gradients (see, e.g., Fattorini \& Ulrich, 2012 and references therein) and/or species dispersal abilities (see Hof et al., 2008). Also, lakes are conceived as ecological islands and thus a relationship of area with species richness may be expected (e.g., Eadie et al., 1986; Lewis \& Magnuson, 2000; Wagner et al., 2014a; Matthews et al., 2015; Neubauer et al., 2015). (2) Gastropod species richness and composition across European lakes are strongly affected by the late Pleistocene glaciations and particularly the timing of deglaciation. We expect an effect of late Pleistocene ice cover on the modern gastropod distributions, considering the evidence for the effect of the LGM on species contemporary distribution (e.g., see Araújo et al., 2008; Svenning et al., 2009; Normand et al., 2011). We hypothesize that lakes of common deglaciation history share a common biogeographical evolution and thus conform in their species compositions. Differences among such lake subsets would allow inferences on independent evolutionary histories and colonization patterns. (3) We expect species composition within the lake groups with common deglaciation history not to be uniform, but rather to reflect geographical and/or environmental distances. Pronounced differences in 
the factors affecting species composition would further suggest that the lake subsets show differences in their evolutionary histories.

\section{Methods}

Dataset

Data on species presences from 898 lakes throughout Europe were collected after an exhaustive literature search, covering 260 scientific papers, books and reports. Search strategy focussed on systematic and faunal studies, supplemented by library catalogue queries. Published faunal lists were then updated by additional records from systematic revisions and specialist studies (e.g., new species or new occurrences). For a complete list of bibliographical sources, see Table S1. To avoid taxonomic inconsistencies, we validated species names as well as genus and family classification using the following sources: Fauna Europaea (de Jong, 2012), Animalbase (WelterSchultes, 2012), MolluscaBase (MolluscaBase, 2015), Glöer (2002) and Kantor et al. (2010). Only native species and subspecies, and two naturalized invaders, i.e., Potamopyrgus antipodarum (Gray, 1843) and Ferrissia fragilis (Tryon, 1863), were considered. Species were considered endemic only when they occurred in one lake in the current dataset (single lake endemics; SLE hereafter); otherwise species restricted to one lake group (for definition of a lake group see below) were considered as regionally confined. Dubious records were omitted from the analysis. The dataset contains 244 valid species and subspecies belonging to 77 genera and 13 families; the study area ranges from $36^{\circ} \mathrm{N}$ to $71^{\circ} \mathrm{N}$ and $-10^{\circ} \mathrm{E}$ to $38^{\circ} \mathrm{E}$ (Fig. 1; Table S1).

\section{Reconstruction of the ice sheets}

To test the potential influence of the timing of deglaciations on lacustrine gastropod species richness and composition, we defined four lake groups (LGs) based on common deglaciation history and geography. Delimitation followed the glacial limits outlines of LGM and YD maxima as reconstructed by Ehlers et al. (2011). LG1 includes 205 lakes that were formed after the YD, i.e., are younger than 11,000 years. LG2 and LG3 contain lakes formed after the LGM, i.e., are younger than c. 18,000 years. Because the two regions represented by LG2 and LG3 are widely disjunct and had different geodynamic evolution we chose to analyse them separately (see Andrén et al., 2011 for LG2 and Kuhlemann, 2007; Sternai et al., 2012 for LG3). LG2 includes 334 lakes north of $50^{\circ}$ latitude and LG3 includes 58 lakes of the Alpine region. Finally, LG4 is comprised of 301 lakes not covered by ice during the last Ice Age. Naturally, the distinction into these four lake subsets is only a coarse proxy for deglaciation history, but precise data on individual geological ages of the lakes are scarcely available. Still, the division constrains the maximum potential age of the lakes in the first three groups. No welldefined age limitation is available for LG4, which combines lakes of different origins and evolutionary histories. Details on the species richness and composition of the four subsets are summarized in Tables 1 and $\mathrm{S} 1$.

\section{Predictor variables}

We selected seven abiotic variables for each lake: (1) surface area, (2) longitude of lake centroid, (3) latitude of lake centroid, (4) lake altitude, (5) lake isolation, (6) annual precipitation and (7) annual mean temperature. Air temperature is considered a reliable proxy for lake temperature and has been used recently to study patterns of European lacustrine fish (Emmrich et al., 2014 and references therein). Polygons of the lakes' outlines were reconstructed in Google ${ }^{\mathrm{TM}}$ Earth 7; surface area, longitude and latitude of the lakes' centroid were calculated in ArcGIS 10 (Esri Inc., 1999-2010) using the feature "Calculate Geometry". As a measure of isolation, we calculated the geographical distance to the nearest lake, using the "Near" tool in ArcGIS. In order to locate the nearest lake, we supplemented our dataset with the Global Lakes and Wetlands Database (GLWD) which contains over 23,000 polygons of European lakes and constitutes the best available source for lakes on a broad-scale (Lehner \& Döll, 2004). The climatic variables were obtained from the WorldClim Database (Hijmans et al., 2005) in the spatial resolution of approximately $1 \mathrm{~km}^{2}$. To attribute the two climatic variables to the lakes, we used the "Zonal Statistics" and the "Sample" tools in ArcGIS.

In addition, depth was only available for a small subset of the data (359 lakes). We performed a linear 


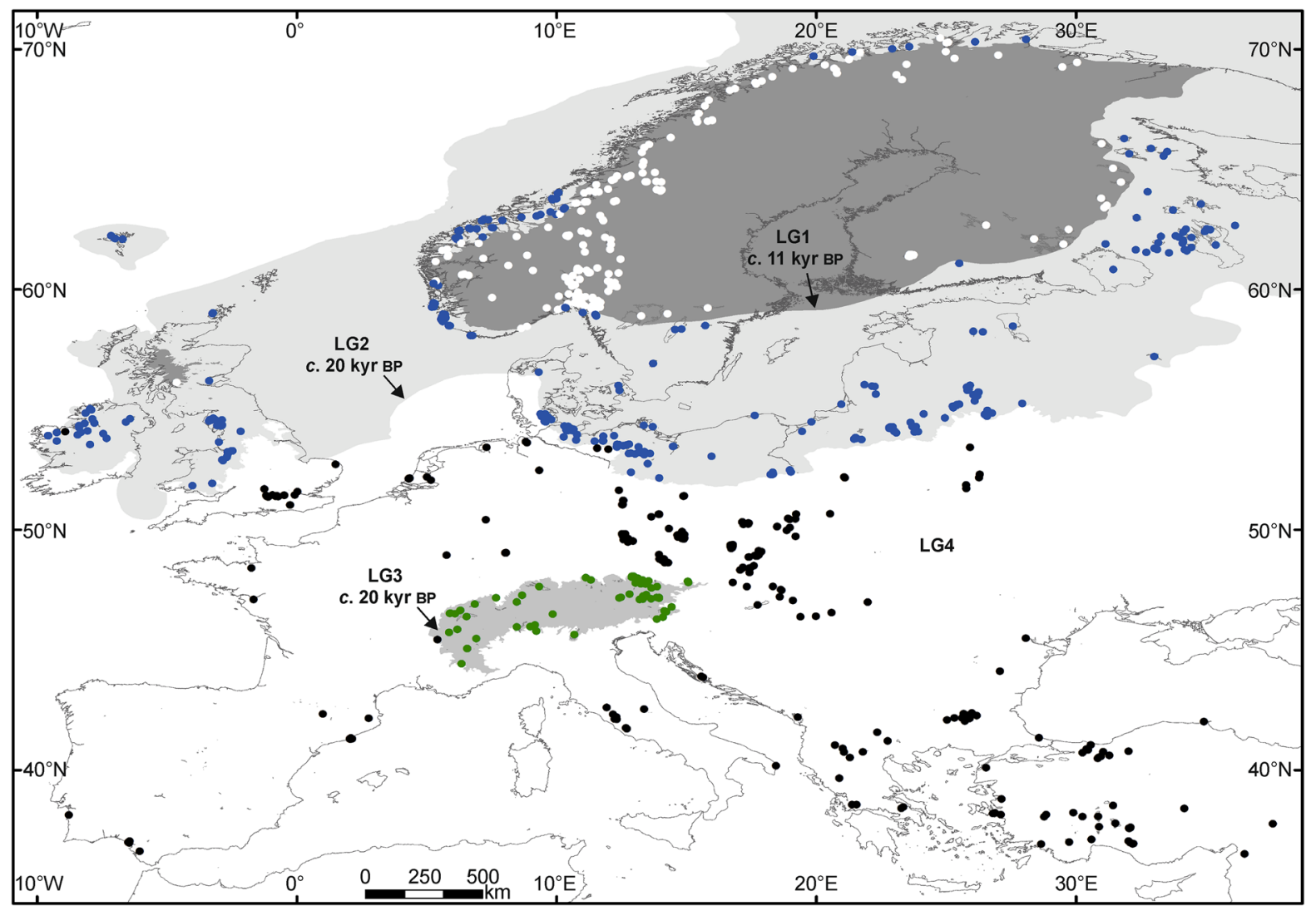

Fig. 1 Map showing the available data on freshwater gastropods in lakes across Europe. The lake groups (LGs) of similar deglaciation history are marked by the limits of the respective ice sheet following Ehlers et al. (2011). LG1 is delimited by the Younger Dryas ice sheet extension; LG2 and LG3 by the extensions during the Last Glacial Maximum in northern Europe and the Alps, respectively. Lakes outside the glacial limits belong to LG4. The geographical coordinate system used is WGS 1984

Table 1 Summary statistics of gastropod species richness in the complete dataset and the four lake groups (LGs) 1-4

\begin{tabular}{lcccccc}
\hline & Lakes & Species & Mean species richness & Richness range & Genera & Families \\
\hline Complete dataset & 898 & $244(102)$ & $7.33 \pm 6.87(7.17 \pm 6.41)$ & $1-66(1-41)$ & $77(44)$ & 13 \\
LG1 & 205 & $39(39)$ & $4.17 \pm 3.58(4.17 \pm 3.58)$ & $1-25(1-25)$ & $22(22)$ & 9 \\
LG2 & 334 & $74(66)$ & $8.87 \pm 7.71(8.85 \pm 7.65)$ & $1-42(1-41)$ & $32(32)$ & 11 \\
LG3 & 58 & $53(50)$ & $10.36 \pm 7.01(10.31 \pm 6.96)$ & $1-27(1-27)$ & $28(27)$ & 10 \\
LG4 & 301 & $216(85)$ & $7.20 \pm 6.78(6.76 \pm 5.33)$ & $1-66(1-34)$ & $75(42)$ & 13 \\
\hline
\end{tabular}

The numbers in parentheses correspond to the summary statistics of species richness after the exclusion of single lake endemics. The number of families remained unchanged

regression of depth and lake species richness to test for a potential relationship, but the correlation was very weak $\left(R^{2}=0.02, P=0.006\right)$. The relationship did not change when depth was included in a multiple regression along with the other variables where the individual contribution of depth was negligible. Because of data unavailability for the majority of investigated lakes and its minor effect on species richness, depth was excluded from further considerations below. 
Data analysis

All parameters were $\log _{10}$-transformed to improve normality. We assessed normality assumptions for species richness and predictor variables using Q-Q plots. Prior to the analysis, we tested for collinearity among the variables, as its existence may bias the estimation of model parameters (Legendre \& Legendre, 1998). To do so, we calculated the variance inflation factor (VIF) of predictor variables using the $\mathrm{R}$ package $\mathrm{HH}$ v. 3.1-14 (Heiberger, 2015) for the complete dataset and for each group separately. As a rule of thumb, VIF values greater than ten indicate the presence of multicollinearity (Quinn \& Keough, 2002).

To test for a possible effect of deglaciation history on species richness of the studied lakes, we constructed three linear models (LMs) for the complete dataset. The first model (LM1) included only the lake groups, i.e., a categorical variable with four levels of deglaciation history (LG1-LG4), the second model (LM2) included only a combination of the abiotic predictors, and the third model (LM3) included a combination of the abiotic predictors and the lake groups. Best variable combinations for LM2 and LM3 based on Akaike's information criterion (AIC) were acquired via stepwise regressions using a backward elimination procedure. In LM3, we included the abiotic variables resulting from the stepwise regression of LM2. The three LMs were subsequently compared using analysis of variance (ANOVA) in order to test if they significantly differed from each other. Furthermore, using the seven abiotic variables, identical to LM2, we performed stepwise multiple regressions using a backward elimination procedure for each lake subset (LG1 to LG4). The adjusted coefficient of determination $\left(R_{\text {adj }}^{2}\right)$ and the AIC were used to evaluate the resulting variable combinations. We measured the individual contributions of the remaining variables of the multiple regression models with hierarchical partitioning using the $\mathrm{R}$ package hier.part v. 1.0-4 (Walsh \& Mac Nally, 2013). In addition, residuals of each final model were checked for spatial autocorrelation using Moran's I index. Spatial autocorrelation is the lack of independence among observations that can lead to potential statistical biases (Legendre \& Legendre, 1998; for in-depth discussion see also Diniz-Filho et al., 2003).

Differences in mean species richness in the LGs were tested using one-way ANOVA with Dunnett-
Tukey-Kramer pairwise multiple comparison post hoc tests adjusted for unequal variances and sample sizes using the R package DTK v. 3.5 (Lau, 2013). Potential variation of species composition among the four LGs was analysed with the Jaccard family of dissimilarity measures for pairwise comparisons, namely $\beta_{\mathrm{jac}}, \beta_{\mathrm{jtu}}$ and $\beta_{\text {jne }}$, which partition species dissimilarity into species replacement without the influence of species richness (spatial turnover component) and species loss (nestedness-resultant component) (Baselga, 2010, 2012). The individual components, i.e., dissimilarity due to species replacement between regions $\left(\beta_{\mathrm{jtu}}\right)$ and due to species loss $\left(\beta_{\text {jne }}\right)$, equal together $\beta_{\text {jac }}$ (Baselga, 2012). The dissimilarity measures were calculated using the R package betapart v. 1.3 (Baselga et al., 2013). Using these analyses, we aim to explore hypotheses (1) and (2).

We used Mantel and partial Mantel tests to analyse compositional dissimilarity within each LG in relation to geographical distances between lakes and lakes' environmental characteristics, corresponding to hypothesis (3). Lake perimeter, altitude, annual precipitation and annual mean temperature were selected as common environmental variables for all LGs. Temperature and precipitation were considered as proxies for climate, altitude for topography and perimeter for habitat availability (see Dehling et al., 2010). The use of Mantel and partial Mantel tests would allow us to control whether the compositional dissimilarity patterns (i.e., beta diversity) within each LG are structured by the lakes' spatial position and/or environmental characteristics (for discussion see Tuomisto \& Ruokolainen, 2006). Dissimilarity, geographical and environmental distance matrices were designed for each LG separately. The $\beta_{\text {jac }}$ dissimilarity matrices were based on the abovementioned measure for pairwise comparisons. We produced environmental distance matrices using Euclidean distances. Geographical distance matrices were produced in ArcGIS using the tool "Generate Near Table", which calculates the geographical distance between each pair of lakes. Mantel and partial Mantel tests were implemented using the R package vegan v. 2.2-1 (Oksanen et al., 2015).

Lake perimeter has been recently facilitated as an approximation for habitat availability (see Dehling et al., 2010), largely corresponding to the extent of shallow-water habitats to which most freshwater gastropods are confined to. However, because of its 
high collinearity with surface area, perimeter was not used in the linear models presented here. In addition, the varied proportion of single lake endemics per LG may have an effect on the results. Thus, the influences of habitat availability (approximated by lake perimeter) as well as the proportion of endemic species were tested in two separate sets of analyses and compared to the results presented here (see Appendix S1).

Statistical analyses were performed in $\mathrm{R}$ version 3.1.1 (R Core Team, 2014) and Moran's I index statistics were calculated in SAM v.4.0 (Rangel et al., 2010).

\section{Results}

\section{Gastropod community composition}

LG1 was represented by $16 \%$ of the total number of species, with an average species richness of 4.17 per lake (Table 1). LG2, LG3 and LG4 were represented by $30.3,21.7$ and $88.5 \%$ of the species and showed an average species richness of 8.87, 10.36 and 7.2, respectively. Dominating family in all subsets except LG4 was the Planorbidae, with 15 (38.5\%), 27 $(36.5 \%)$ and $20(37.7 \%)$ species in LG1, LG2 and LG3, respectively. LG4 was the only subset with representatives of all 13 families. In LG4, the dominating and most diverse family was the Hydrobiidae with $84(38.9 \%)$ species. The average richness differed significantly across the LGs (ANOVA $F_{3,894}=25.89$; $P<0.0001)$, but not for all pairwise comparisons (Table S2). All pairs were significant $(P<0.01)$ except LG3-LG2 $(P=0.39)$.

102 species remained when SLE were excluded, but average species richness and quantitative differences between the LGs remained similar (ANOVA $F_{3,894}=30.48 ; P<0.0001$; Tables 1, S2).

Patterns of species richness and composition

Given the lack of multicollinearity (VIF values $<7.5$ ), all variables were included in the models (Table S3). The spatial correlograms created for the model residuals of the LMs, the complete dataset and the four LGs, revealed low spatial autocorrelation in the first distance classes (Fig. S1). However, regression coefficients are not severely influenced by the presence of residual spatial autocorrelation within these ranges (see Hawkins et al., 2007). The explanatory power of LM1 was significant but poor $\left(F_{3}, 894=\right.$ 27.56, $R_{\text {adj. }}^{2}=0.0816, P<0.0001$, Table S4). In LM2, latitude and altitude were excluded by the stepwise variable selection procedure, while the rest of the predictors explained only a moderate part of the variation in species richness $\left(F_{5}, \quad 892=72.75\right.$, $R_{\text {adj. }}^{2}=0.2857, P<0.0001$, Table 2). LM3 included a combination of abiotic variables, LGs and interactions between lake characteristics and deglaciation history $\left(F_{20,877}=38.39, R_{\text {adj. }}^{2}=0.4547, P<0.0001\right.$, Table S4) and performed significantly better than LM1 and LM2 (both $P<0.0001$ ). The three LMs indicate that variation in lacustrine gastropod richness of Europe is partially explained by environmental, spatial characteristics, and deglaciation history. Multiple regressions showed that the determinants of gastropod species richness varied among the subsets (Fig. 2; Table 2; Fig. S2). In LG1, species richness increases significantly with decreasing latitude, altitude and precipitation and increasing area, accounting together for $32.36 \%$ of the variation; the main contributor here was precipitation (Fig. 2). Variation in species richness in LG2 was related negatively to latitude, altitude, precipitation and distance and positively to longitude and area. Here, the individual contribution of latitude was the highest, followed by precipitation. In LG3, latitude, temperature and precipitation were maintained during the stepwise removal. Almost $58 \%$ of the variation in species richness was explained by these variables, but only temperature showed a considerably high individual contribution. For LG4, latitude, area and temperature were maintained, accounting for $38.4 \%$ of the variation in species richness. Area was the predictor with the highest contribution.

Pairwise beta diversity analysis revealed differences in species composition between the LGs (Table 3). Beta diversities between LG4 and each of the other LGs $(0.78-0.85)$ were distinctly higher than those for the remaining combinations (0.46-0.47) (Table 3). Species replacement was higher than species loss for the pairs LG1-LG3, LG2-LG3 and LG2-LG4 (Fig. 3; Table 3). For the remaining pairs (LG1-LG2, LG1-LG4 and LG3-LG4), beta diversity patterns were primarily caused by species loss (Fig. 3; Table 3).

Mantel tests showed that beta diversity $\left(\beta_{\mathrm{jac}}\right)$ was positively correlated with geographical and environmental distance for all LGs, although the strength of 
Table 2 Variable sets affecting gastropod species richness of European lakes as proposed by stepwise multiple regressions (MR)

\begin{tabular}{|c|c|c|c|c|c|c|c|c|}
\hline & $R_{\text {adj }}^{2}$ & $P$ & Lowest AIC & $\Delta \mathrm{AIC}$ & Variables & Est. MR & $P \mathrm{MR}$ & Ind. \\
\hline \multirow[t]{5}{*}{ Complete dataset (LM2) } & \multirow[t]{5}{*}{0.2857} & \multirow[t]{5}{*}{$<0.0001$} & \multirow[t]{5}{*}{-1943.15} & \multirow[t]{5}{*}{2.27} & Long & 0.0851 & 0.0761 & 0.015 \\
\hline & & & & & Area & 0.1025 & $<0.0001$ & 0.109 \\
\hline & & & & & Temp & 0.6407 & $<0.0001$ & 0.087 \\
\hline & & & & & Prec & -0.7780 & $<0.0001$ & 0.074 \\
\hline & & & & & Isol & -0.0985 & 0.0013 & 0.005 \\
\hline \multirow[t]{4}{*}{ LG1 } & \multirow[t]{4}{*}{0.3236} & \multirow[t]{4}{*}{$<0.0001$} & \multirow[t]{4}{*}{-530.46} & \multirow[t]{4}{*}{5.35} & Lat & -4.9786 & $<0.0001$ & 0.095 \\
\hline & & & & & Alt & -0.1790 & $<0.0001$ & 0.049 \\
\hline & & & & & Area & 0.0245 & 0.141 & 0.006 \\
\hline & & & & & Prec & -0.9223 & $<0.0001$ & 0.188 \\
\hline \multirow[t]{6}{*}{ LG2 } & \multirow[t]{6}{*}{0.5511} & \multirow[t]{6}{*}{$<0.0001$} & \multirow[t]{6}{*}{-816.95} & \multirow[t]{6}{*}{0.21} & Lat & -8.3673 & $<0.0001$ & 0.230 \\
\hline & & & & & Long & 0.3053 & $<0.0001$ & 0.052 \\
\hline & & & & & Alt & -0.1299 & 0.0005 & 0.017 \\
\hline & & & & & Area & 0.1153 & $<0.0001$ & 0.094 \\
\hline & & & & & Prec & -0.4302 & 0.0115 & 0.134 \\
\hline & & & & & Isol & -0.1655 & 0.0031 & 0.032 \\
\hline \multirow[t]{3}{*}{ LG3 } & \multirow[t]{3}{*}{0.5753} & \multirow[t]{3}{*}{$<0.0001$} & \multirow[t]{3}{*}{-161.13} & \multirow[t]{3}{*}{4.78} & Lat & 10.5123 & 0.0131 & 0.047 \\
\hline & & & & & Temp & 1.4826 & $<0.0001$ & 0.412 \\
\hline & & & & & Prec & -1.0471 & 0.0614 & 0.138 \\
\hline \multirow[t]{3}{*}{ LG4 } & \multirow[t]{3}{*}{0.384} & \multirow[t]{3}{*}{$<0.0001$} & \multirow[t]{3}{*}{-761.6} & \multirow[t]{3}{*}{6.21} & Lat & 3.2864 & $<0.0001$ & 0.068 \\
\hline & & & & & Area & 0.1579 & $<0.0001$ & 0.312 \\
\hline & & & & & Temp & 0.3299 & 0.112 & 0.010 \\
\hline
\end{tabular}

Shown are the adjusted $R^{2}\left(R_{\mathrm{adj}}^{2}\right)$ and $P$ values $(P)$ of the MRs, Akaike's information criterion (AIC), the difference between initial and final Akaike's information criterion ( $\triangle \mathrm{AIC})$, the estimate of the multiple regression (Est. MR), significance of the variables in the multiple regression $(P \mathrm{MR})$ and the independent contribution for each variable as provided by hierarchical partitioning results (Ind.) Lat Latitude (decimal degrees), Long longitude (decimal degrees), Alt altitude (metres), Area lake surface area ( $\left.\mathrm{km}^{2}\right)$, Temp mean annual temperature $\left({ }^{\circ} \mathrm{C}\right)$, Prec annual precipitation $(\mathrm{mm})$, Isol isolation $(\mathrm{km})$

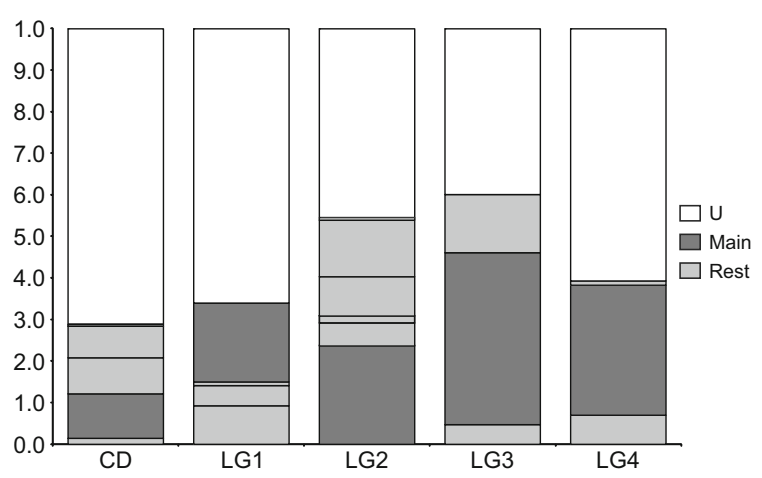

Fig. 2 Partition of variance based on the multiple regression results of the complete dataset (CD) and each lake group (LG). $\mathrm{U}$, the unexplained variation; Main, the variation of the predictor with the highest individual contribution, i.e., area (CD), precipitation (LG1), latitude (LG2), temperature (LG3) and area (LG4); Rest, the variation attributed to the remaining predictors (for detailed results see Table 2)
Table 3 Pairwise beta diversity of the lake groups (LGs) 1-4 computed with the Jaccard dissimilarity measure (Baselga, 2012)

\begin{tabular}{llll}
\hline Groups & $\beta_{\text {jac }}$ & $\beta_{\text {jtu }}$ & $\beta_{\text {jne }}$ \\
\hline LG1-LG2 & 0.47 & 0 & 0.47 \\
LG1-LG3 & 0.46 & 0.30 & 0.16 \\
LG1-LG4 & 0.85 & 0.23 & 0.62 \\
LG2-LG3 & 0.47 & 0.29 & 0.18 \\
LG2-LG4 & 0.78 & 0.44 & 0.34 \\
LG3-LG4 & 0.80 & 0.26 & 0.54
\end{tabular}

$\beta_{\mathrm{jac}}$ is the overall beta diversity, $\beta_{\mathrm{jtu}}$ and $\beta_{\mathrm{jne}}$ are the dissimilarity components referring to species replacement and species loss, respectively

the correlation varied (Table 4). Partial Mantel tests revealed that beta diversity was significantly correlated with geographical distance in LG1, LG2 and 
LG4 after the effect of environmental distance was partialled out. On the other hand, beta diversity was significantly correlated with environmental distance after the exclusion of the effect of geographical distance only for LGs $2-4$.

\section{Discussion}

\section{Species richness}

Historical constraints are a well-known determinant of large-scale richness patterns, although their influence can vary considerably among groups of organisms (e.g., Reyjol et al., 2007; Araújo et al., 2008; Svenning et al., 2009). The low to moderate explanatory power of the LMs and multiple regression models indicates that the selected physiographical and climatic factors could not efficiently predict lacustrine gastropod species richness, neither on a pan-European scale nor within the predefined subsets. Likewise, deglaciation history of lakes was a significant predictor but its explanatory power was also moderate. Nevertheless, we detected significant differences in species richness and composition among the lake subsets of different glacial history. Consistent with other studies (e.g., Svenning et al., 2009), we propose that additional forces, beyond those modelled here, are shaping lacustrine gastropod distribution and richness patterns across Europe. From a historical point of view, such factors may be distance from refuge locations, post-

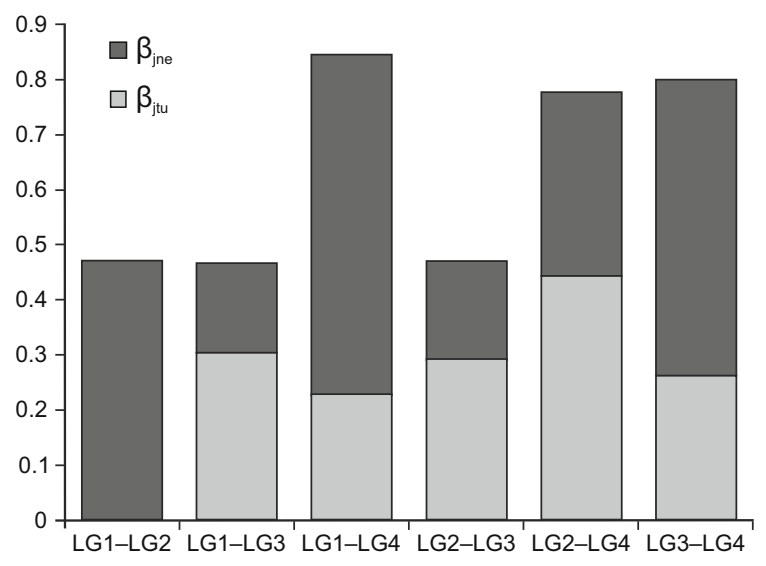

Fig. 3 Partitioning of beta diversity into spatial turnover $\left(\beta_{\mathrm{jtu}}\right)$ and nestedness-resultant $\left(\beta_{\text {jne }}\right)$ components for lacustrine gastropod assemblages in the lake groups (LGs) $1-4$. The sum of $\beta_{\mathrm{jtu}}$ and $\beta_{\mathrm{jne}}$ equals to $\beta_{\mathrm{jac}}$ glacial migration patterns, human influence (cf. Svenning et al., 2009 and references therein) as well as the persistence and retreat pattern of the ice shields (Hawkins \& Porter, 2003).

On a local scale, gastropod species richness in lakes has been associated with chemical characteristics, lake surface area, altitude and geo-position, i.e., isolation of the lake (Aho, 1978; Økland, 1990; Lewis \& Magnuson, 2000). In our study, area was a significant predictor on the pan-European scale, although the contribution to the explained variation was small as also shown for a subset of European pond gastropods (Swiss lakes) by Oertli et al. (2002). Similarly, correlations with lake isolation and climate variables are significant, but with low explanatory power. On a larger scale, variation of taxonomic richness is usually linked to climate (Currie et al., 2004), whereas the impact of past conditions can still affect today's distributions (Araújo et al., 2008). Although the classification of lakes into LGs according to their glacial history could not explain the variation in species richness (LM1), the explanatory power significantly improved when the effect of deglaciation history was added to the model (LM3). As a corroboration of this hypothesis, the explanatory power of the multiple regressions improved in comparison with the climatic model (LM2) and differences between species richness and composition emerged, when the faunas were divided into subsets of common glacial, hence biogeographical, history.

Lakes of LG1 are presently distributed north of $56^{\circ} \mathrm{N}$ latitude. During the LGM and YD, however, this area was completely glaciated. None of the presently existing lakes were formed before the retreat of the glaciers after the YD and they are younger than 11,000 years. Many of those lakes are even younger, as Scandinavia was fully ice-free only after 9,800 years BP (Andrén et al., 2011). Occurrences of at least five subfossil freshwater gastropod species from deposits dated back to 9,000 years BP in southern central Norway (ca $59^{\circ} \mathrm{N}-60^{\circ} \mathrm{N}$ ) (Økland, 1990) and 9,500-6,700 years BP in northern Finland (ca $\left.66^{\circ} \mathrm{N}-68^{\circ} \mathrm{N}\right)$ (Salmi, 1963; Vasari et al., 1963) indicate a rapid recolonization. Despite the high active- and passive-dispersal capabilities of freshwater gastropods (see Kappes \& Haase, 2012 for a review), only few species have reached the northernmost lakes. A permanent establishment of more diverse gastropod faunas that far north is probably impeded by the 
Table 4 Results from Mantel and partial Mantel tests, showing correlations of species dissimilarity distance (expressed by $\beta_{\text {jac }}$ ) with geographical and environmental distance for the four lake groups (LGs) 1-4

\begin{tabular}{|c|c|c|c|c|}
\hline & LG1 & LG2 & LG3 & LG4 \\
\hline \multicolumn{5}{|c|}{ Geographical distance } \\
\hline$r$ & 0.26 & 0.31 & 0.09 & 0.27 \\
\hline$P$ & $<0.001$ & $<0.001$ & 0.03 & $<0.001$ \\
\hline \multicolumn{5}{|c|}{ Environmental distance } \\
\hline$r$ & 0.07 & 0.38 & 0.53 & 0.19 \\
\hline$P$ & 0.04 & $<0.001$ & $<0.001$ & $<0.001$ \\
\hline \multicolumn{5}{|c|}{ Effect of environmental distance removed } \\
\hline$r$ & 0.26 & 0.17 & 0.03 & 0.22 \\
\hline$P$ & $<0.001$ & $<0.001$ & 0.24 & $<0.001$ \\
\hline \multicolumn{5}{|c|}{ Effect of geographical distance removed } \\
\hline$r$ & 0.002 & 0.28 & 0.52 & 0.12 \\
\hline$P$ & 0.5 & $<0.001$ & $<0.001$ & $<0.001$ \\
\hline
\end{tabular}

Statistical significance $(P)$ of Spearman correlations $(r)$ was determined using 9,999 permutations. Significant correlations are in italics

extreme climatic conditions, resulting in prolonged freezing periods. The richest lakes in LG1 are near the southern margins of the former YD ice shield and are supposedly the oldest lakes of that group. Although we would expect fewer species to be tolerant to the boreal climate, temperature and precipitation did not prove to be dominant limiting factors for the establishment of rich lake faunas in LG1. Consequently, a relation of the low species richness compared to the other LGs with the young geological age of the lakes is likely. In other words, it is possible that many species presently confined to lower latitudes are still expanding their northern ranges. This conclusion is consistent with other studies, which proposed that certain European plant species are still expanding from their ice-age refugia (see Svenning et al., 2008 and references therein).

Although characterized by comparable age constraints, the predictor variables yielded quite different results for LG2 and LG3 (Fig. 2; Table 2). The differences are likely related to the disjunct geographical location and the varied topographical and climatic features of the two areas (Table S5). For LG2, the high species richness can be partly attributed to the fact that it includes a series of lakes and freshwater lagoons around the Baltic Sea as well as two of the largest lakes of the dataset (Ladoga and Onega). Our results are in agreement with Dehling et al. (2010), who found that lentic species richness is the highest in the peri-Baltic region. The peri-Baltic lakes are theoretically easily accessible to freshwater gastropods as the area is relatively flat with well-connected and extended lakewetland systems and many outflows of major rivers.

Only temperature yielded a high individual contribution in the geographically limited LG3 (Fig. 2). Lakes attributed to that group show an extensive altitudinal range (62-2362 $\mathrm{m}$ a.s.1.). Surprisingly, however, altitude was not found as important predictor here as it was for other geographical regions (e.g., Zhao et al., 2006). Although LG3 was glaciated during the LGM, still pockets of land free of ice existed, wherefore it is possible that gastropods had survived the glacial period in marginal alpine areas (Cordellier \& Pfenninger, 2009; Harl et al., 2014). Moreover, most of the lakes in LG3 are situated in peri-Alpine valleys and were almost immediately formed after the retreat of the ice shields (e.g., Lake Geneva; Favre, 1927). Therefore, the higher species richness of LGs 2 and 3 compared to LG1 might be explained by their prolonged geological history and, accordingly, the longer timeframe available for recolonization.

The lower explanatory power of the multiple regression model for LG4 can be linked to the rather heterogeneous composition of lakes in terms of origin and faunal evolution. In comparison with LGs1-3, the lakes in LG4 do not share a common (glacial) history and are scattered across Europe (Fig. 1), making this group an artificial unit. Average species richness is lower than for LG2 and LG3, but local richness includes the highest values in the whole dataset, owed to the diverse faunas of the Balkan lakes (e.g., Lake Ohrid with 66 species). Unlike in the first three LGs, surface area was the strongest predictor and accounted for $31.2 \%$ of variation in species richness. Lakes of LG4 were lesser influenced by the Ice Ages and their faunal history often dates further back in time, providing more time for species accumulation. Accordingly, those lakes are probably closer to faunal equilibrium in regards to surface area, while those of LGs $1-3$ are still being recolonized and may not have yet reached the stage where area is a limiting factor for species richness (Eadie et al., 1986; Wagner et al., 2014a). Clarification of species richness patterns within this lake group is beyond the scope of the present study. 
Species composition

It has been previously shown that beta diversity patterns can be linked to historical processes (Graham et al., 2006). Thus, we would expect a more detailed insight into the differentiation between and within the LGs as provided by the beta diversity analysis. The selection of a richness-independent index allows conclusions on the differences in gastropod composition among the four LGs.

Our results show that among the glacially affected LGs1-3 the variation in species richness is moderate and differences between LG2 and LG1 to LG3 are mainly due to species replacement. This is closely related to the influence of the geographical position of the respective LGs. Both Alpine and northern European lakes are inhabited by generalist species with wide environmental tolerances (e.g., Økland, 1990; Sturm, 2007 and references therein). In addition, LGs1-2 contain a number of typical boreal taxa as well as species associated with brackish or coastal waters (see Økland, 1990; Welter-Schultes, 2012). The moderate dissimilarity between LG1 and LG2 is mainly a result of nestedness, indicating species loss towards the north (see also Baselga, 2008); hence, not all species in LG2 could yet colonize LG1.

Not surprisingly, the gastropod faunas of the three glacially constrained LGs, where species distributions are a result of post-glacial recolonization, is more similar to each other than to LG4 (Table 3). The faunal similarity among LGs $1-3$ is more likely explained by the dominance of pulmonates, i.e., Planorbidae and Lymnaeidae. Consistent with the Holocene fossil record for Scandinavian freshwater gastropods (e.g., Salmi, 1963; Vasari et al., 1963; Bennike et al., 1998), our results indicate that pulmonates are the major colonizers of newly formed lakes, as they are generally characterized by good dispersal abilities, broad environmental tolerance and are successful colonizers of new environments (see Strong et al., 2008; Kappes \& Haase, 2012 and references therein; see species examples in Cordellier \& Pfenninger, 2008, 2009). Thus, widespread gastropods mainly live in LGs1-3, i.e., lakes that formed after the termination of the late Pleistocene glaciations. These species could have reached the LGs1-3 not only from southern but also central and northern European refugia (Cordellier \& Pfenninger, 2008, 2009) located in the area of LG4. This hypothesis is supported by the beta diversity analysis, indicating species loss as the main component explaining dissimilarity between LGs 1 and 3 and LG4; for LG2 beta diversity is about equally partitioned into species loss and replacement. This implies that gastropod faunas of formerly glaciated (typically less diverse) areas are partly nested within nonglaciated ones (compare cf. Baselga, 2008), conforming to hypothesis (2). On the other hand, our results for LG4, e.g., high number of SLE (see Table 1), are in agreement with studies suggesting that species with narrow ranges are mainly restricted to the southern parts of Europe, partly because of their poor ability to adjust to contemporary climate (see Araújo et al., 2008 and references therein) or their weak dispersal abilities (see Fattorini \& Ulrich, 2012).

In support of hypothesis (3), the Mantel and partial Mantel tests (Table 4) indicate that within the LGs compositional dissimilarity of lakes is related to geographical and environmental features, demonstrating that both the species' dispersal history and response to environmental characteristics of the lakes shape the observed beta diversity patterns. In particular, the number of shared species in lakes of LG1 is independent of the lakes' environmental characteristics but apparently reflect geographical distances between the lakes. Thus, species composition in LG1 is random but spatially autocorrelated due to dispersal limitation of species (see Tuomisto \& Ruokolainen, 2006 and references therein). Although lakes in LG1 are characterized by widespread species, differences in the mode of dispersal, e.g., active versus passive (see Kappes \& Haase, 2012), in combination with different post-glacial recolonization routes (e.g., Refseth et al., 1998; Tollefsrud et al., 2008), time from deglaciation (see Andrén et al., 2011) and the presence of geographical barriers may explain our findings. The partial Mantel tests showed that environmental distances are more important than geographical distances in LG2. This result is not entirely unexpected; the limnic phase of the Baltic Sea in the early Holocene (see Andrén et al., 2011) and the high connectivity of present lakes facilitated dispersal of species largely unhindered by geographical distance (or boundaries) in LG2. Similarly, species composition in lakes of LG3 is strongly correlated to environmental gradients. Our results agree with a previous study suggesting the colonization patterns of freshwater gastropods in Alpine lakes to depend on the species' ecological preferences (Sturm, 2007). The lack of correlation 
between species composition and geographical distance may root in the complex Alpine topography. Lakes located in small geographical distance from each other are often isolated by high mountain ranges, posing major constraints on gastropod dispersal. Species composition in LG4, in contrast, was mainly correlated to geographical distances. The high number of SLE as well as species with low dispersal capability, e.g., habitat specialists such as some hydrobiids (Strong et al., 2008), could explain this pattern.

\section{Synthesis}

Our results indicate that the modern distribution of lacustrine gastropods in Europe is still shaped by terminal Pleistocene deglaciation history. Differences in selected predictor variables between LGs suggest that there is no fixed factor controlling richness patterns across Europe. A latitudinal gradient is present in all four LGs but not in the complete dataset, with precipitation and latitude being the strongest predictors for the northernmost lake groups (LG1 and LG2). The results of the general linear models partly support hypotheses (1) and (2). More precisely, the moderate explanatory power of all models, i.e., LMs and multiple regression models for the LGs separately, and the absence of clear geographical patterns suggest that post-glacial recolonization is still ongoing and lake faunas in LGs1-3 are not in a stable equilibrium yet, supporting previous conclusions on species richness patterns of European freshwater animals in general (Dehling et al., 2010). Deglaciation history and related processes are proposed as principal causes; lentic species, in contrast to lotic ones, are closer to equilibrium (Dehling et al., 2010). Overall, based on the multiple regression results, we suggest that additional forces beyond those modelled here are responsible for species richness-not only at European scale but also within the LGs. Other aspects such as habitat diversity, trophic status, total hardness, $\mathrm{pH}$ value, human impact and interaction with other species (e.g., predator-prey relationships), which potentially may explain additional parts of the variation in species richness, could not be considered in the present study, largely due to data deficiency on a panEuropean scale.

The present patterns are considerably affected by gastropod dispersal, which is mostly limited to passive dispersal, e.g., introduction via waterfowl, large mammals or anthropogenic vectors (Kappes \& Haase, 2012; van Leeuwen et al., 2012, 2013). Therefore, any historical signal in their distribution pattern can potentially be rapidly obscured. Investigation of the impact of transport by aquatic birds needs detailed analyses of their migratory pathways (Reynolds et al., 2015) and interactions with specific gastropod groups. Differences in richness between the LGs is probably a combination of the timing of deglaciation during the late Pleistocene, differences in post-glacial recolonization and dispersal capabilities of lacustrine gastropods (see also Hof et al., 2008; Dehling et al., 2010). Furthermore, the beta diversity between the LGs is in fact still very high in the light of the many thousand years of possible migration and introduction. The overall high dissimilarity between LGs1-3 and LG4 is related to the presence of many regionally confined species in the latter group, even with the exclusion of the SLE (see Appendix S1). As those lakes were not covered by ice during the last Ice Age, faunal development was less constrained. Thus, some of them could have acted as refugia during the glacial periods or as speciation centres (e.g., Albrecht et al., 2006).

The correlation of geographical and/or environmental distances with beta diversity showed species distribution patterns are not uniform within the LGs, which is in line with hypothesis (3). The varied degree of correlation with either geographical or environmental distances suggests differences in the lakes' faunal histories. All the correlations, however, fully confirmed our expectancies, corresponding to differences in the time elapsed since deglaciation, the LG's geographical location, and the current environmental and topographical conditions.

The current study is an important step towards understanding large-scale patterns of the limnic gastropod fauna of Europe. As broad-scale studies on faunal patterns in aquatic ecosystems are generally quite restricted (Heino, 2011) and the impact of deglaciations on the evolution and dispersal of invertebrate taxa are inadequately known, we expect this contribution to stimulate investigations on the historical components explaining distribution patterns of other European freshwater biotas as well.

Acknowledgments We thank: R.M. Albuquerque de Matos, V.V. Anistratenko, N. Bonada, P. Djursvoll, Z. Féher, M. Jeffries, G.S. Karaman, A. Kołodziejczyk, P. Nõges, M. Özbek, 
P. Raposeiro, M. Rieradevall, K. Schniebs, T. Timm, G. Urbanič, M.V. Vinarski and M. Zeki Yildirim for their assistance with literature review. We also thank A. Oikonomou, K. Rijsdijk, E. Tjørve and anonymous reviewers for valuable suggestions. The project was financially supported by the Austrian Science Fund (FWF Project No. P25365-B25: "Freshwater systems in the Neogene and Quaternary of Europe: Gastropod biodiversity, provinciality, and faunal gradients").

Open Access This article is distributed under the terms of the Creative Commons Attribution 4.0 International License (http:// creativecommons.org/licenses/by/4.0/), which permits unrestricted use, distribution, and reproduction in any medium, provided you give appropriate credit to the original author(s) and the source, provide a link to the Creative Commons license, and indicate if changes were made.

\section{References}

Aho, J., 1978. Freshwater snail populations and the equilibrium theory of island biogeography. II. Relative importance of chemical and spatial variables. Annales Zoologici Fennici 15: $155-164$.

Albrecht, C., S. Trajanovski, K. Kuhn, B. Streit \& T. Wilke, 2006. Rapid evolution of an ancient lake species flock: freshwater limpets (Gastropoda: Ancylidae) in the Balkan Lake Ohrid. Organisms, Diversity \& Evolution 6: 294-307.

Andrén, T., S. Björck, E. Andrén, D. Conley, K. Lambeck, L. Zillén \& J. Anjar, 2011. The Development of the Baltic Sea Basin During the Last 130 ka. In Harff, J., S. Björck \& P. Hoth (eds), The Baltic Sea Basin as a Natural Laboratory. Springer, Berlin: 75-97.

Araújo, M. B., D. Nogues-Bravo, J. A. F. Diniz-Filho, A. M. Haywood, P. J. Valdes \& C. Rahbek, 2008. Quaternary climate changes explain diversity among reptiles and amphibians. Ecography 31: 8-15.

Baselga, A., 2008. Determinants of species richness, endemism and turnover in European longhorn beetles. Ecography 31: 263-271.

Baselga, A., 2010. Partitioning the turnover and nestedness components of beta diversity. Global Ecology and Biogeography 19: 134-143.

Baselga, A., 2012. The relationship between species replacement, dissimilarity derived from nestedness, and nestedness. Global Ecology and Biogeography 21: 1223-1232.

Baselga, A., D. Orme, S. Villeger, J. De Bortoli \& F. Leprieur, 2013. betapart: Partitioning Beta Diversity into Turnover and Nestedness Components. R package version 1.3. http:// CRAN.R-project.org/package=betapart.

Benke, M., M. Brändle, C. Albrecht \& T. Wilke, 2011. Patterns of freshwater biodiversity in Europe: lessons from the spring snail genus Bythinella. Journal of Biogeography 38 : 2021-2032.

Bennike, O., W. Lemke \& J. B. Jensen, 1998. Fauna and flora in submarine early-Holocene lake-marl deposits from the southwestern Baltic Sea. The Holocene 8: 353-358.

Cordellier, M. \& M. Pfenninger, 2008. Climate-driven range dynamics of the freshwater limpet, Ancylus fluviatilis
(Pulmonata, Basommatophora). Journal of Biogeography 35: $1580-1592$.

Cordellier, M. \& M. Pfenninger, 2009. Inferring the past to predict the future: climate modelling predictions and phylogeography for the freshwater gastropod Radix balthica (Pulmonata, Basommatophora). Molecular Ecology 18: 534-544.

Currie, D. J., G. G. Mittelbach, H. V. Cornell, R. Field, J.-F. Guégan, B. A. Hawkins, D. M. Kaufman, J. T. Kerr, T. Oberdorff, E. O'Brien \& J. R. G. Turner, 2004. Predictions and tests of climate based hypotheses of broad-scale variation in taxonomic richness. Ecology Letters 7: 1121-1134.

de Jong, Y. S. D. M., 2012. Fauna Europaea Version 2.5. http:// www.faunaeur.org.

Dehling, D. M., C. Hof, M. Brändle \& R. Brandl, 2010. Habitat availability does not explain the species richness patterns of European lentic and lotic freshwater animals. Journal of Biogeography 37: 1919-1926.

Diniz-Filho, J. A. F., L. M. Bini \& B. A. Hawkins, 2003. Spatial autocorrelation and red herrings in geographical ecology. Global Ecology and Biogeography 12: 53-64.

Eadie, J. Mc A, T. A. Hurly, R. D. Montgomerie \& K. L. Teather, 1986. Lakes and rivers as islands: species-area relationships in the fish faunas of Ontario. Environmental Biology of Fishes 15: 81-89.

Ehlers, J., P. L. Gibbard \& P. D. Hughes, 2011. Quaternary Glaciations - Extent and Chronology, 1st ed. Elsevier, Amsterdam. http://booksite.elsevier.com/9780444534477/ index.php.

Emmrich, M., S. Pédron, S. Brucet, I. J. Winfield, E. Jeppesen, P. Volta, C. Argillier, T. L. Lauridsen, K. Holmgren, T. Hesthagen \& T. Mehner, 2014. Geographical patterns in the body-size structure of European lake fish assemblages along abiotic and biotic gradients. Journal of Biogeography 41: 2211-2233.

Esri Inc., 1999-2010. ArcGIS for Desktop: Release 10. Environmental Systems Research Institute, Redlands, CA.

Fattorini, S. \& W. Ulrich, 2012. Spatial distributions of European Tenebrionidae point to multiple postglacial colonization trajectories. Biological Journal of the Linnean Society 105: 318-329.

Favre, J., 1927. Les mollusques post-glaciaires et actuels du bassin de Genève. Mémoires de la Société de Physique et d'Histoire Naturelle de Genève 40: 171-434.

Fløjgaard, C., S. Normand, F. Skov \& J.-C. Svenning, 2011. Deconstructing the mammal species richness pattern in Europe - towards an understanding of the relative importance of climate, biogeographic history, habitat heterogeneity and humans. Global Ecology and Biogeography 20: 218-230.

Glöer, P., 2002. Die Tierwelt Deutschlands, 73. Teil: Die Süßwassergastropoden Nord- und Mitteleuropas. Bestimmungsschlüssel, Lebensweise, Verbreitung. ConchBooks, Hackenheim.

Graham, C. H., C. Moritz \& S. E. Williams, 2006. Habitat history improves prediction of biodiversity in rainforest fauna. Proceedings of the National Academy of Sciences of the United States of America 103: 632-636.

Harl, J., M. Duda, L. Kruckenhauser, H. Sattmann \& E. Haring, 2014. In search of glacial refuges of the land snail Orcula 
dolium (Pulmonata, Orculidae) - an integrative approach Using DNA sequence and fossil data. PLoS One 9: e96012.

Hawkins, B. A. \& E. E. Porter, 2003. Relative influences of current and historical factors on mammal and bird diversity patterns in deglaciated North America. Global Ecology and Biogeography 12: 475-481.

Hawkins, B. A., R. Field, H. V. Cornell, D. J. Currie, J. F. Guegan, D. M. Kaufman, J. T. Kerr, G. G. Mittelbach, T. Oberdorff, E. M. O’Brien, E. E. Porter \& J. R. G. Turner, 2003. Energy, water, and broad-scale geographic patterns of species richness. Ecology 84: 3105-3117.

Hawkins, B. A., J. A. F. Diniz-Filho, L. M. Bini, P. De Marco \& T. M. Blackburn, 2007. Red herrings revisited: spatial autocorrelation and parameter estimation in geographical ecology. Ecography 30: 375-384.

Heiberger, R. M., 2015. HH: Statistical Analysis and Data Display: Heiberger and Holland. R package version 3.1-14. http://CRAN.R-project.org/package=HH.

Heino, J., 2011. A macroecological perspective of diversity patterns in the freshwater realm. Freshwater Biology 56: 1703-1722.

Hewitt, G., 1999. Post-glacial re-colonization of European biota. Biological Journal of the Linnean Society 68: 87-112.

Hewitt, G. M., 2000. The genetic legacy of the Quaternary ice ages. Nature 405: 907-913.

Hijmans, R. J., S. E. Cameron, J. L. Parra, P. G. Jones \& A. Jarvis, 2005. Very high resolution interpolated climate surfaces for global land areas. International Journal of Climatology 25: 1965-1978.

Hof, C., M. Brändle \& R. Brandl, 2008. Latitudinal variation of diversity in European freshwater animals is not concordant across habitat types. Global Ecology and Biogeography 17: 539-546.

Kantor, Y. I., M. V. Vinarski, A. A. Schileyko \& A. V. Sysoev, 2010. Catalogue of the continental mollusks of Russia and adjacent territories. Version 2.3.1. http://www.ruthenica. com/documents/Continental_Russian_molluscs_ver2-3-1. pdf.

Kappes, H. \& P. Haase, 2012. Slow, but steady: dispersal of freshwater molluscs. Aquatic Sciences 74: 1-14.

Kuhlemann, J., 2007. Paleogeographic and paleotopographic evolution of the Swiss and Eastern Alps since the Oligocene. Global and Planetary Change 58: 224-236.

Lau M. K., 2013. DTK: Dunnett-Tukey-Kramer Pairwise Multiple Comparison Test Adjusted for Unequal Variances and Unequal Sample Sizes. R package version 3.5. http:// CRAN.R-project.org/package=DTK.

Legendre, P. \& L. Legendre, 1998. Numerical Ecology, 2nd ed. Elsevier, Amsterdam.

Lehner, B. \& P. Döll, 2004. Development and validation of a global database of lakes, reservoirs and wetlands. Journal of Hydrology 296: 1-22.

Lewis, D. B. \& J. J. Magnuson, 2000. Landscape spatial patterns in freshwater snail assemblages across Northern Highland catchments. Freshwater Biology 43: 409-420.

Matthews, T. J., F. Guilhaumon, K. A. Triantis, M. K. Borregaard \& R. J. Whittaker, 2015. On the form of species-area relationships in habitat islands and true islands. Global Ecology and Biogeography. doi:10.1111/geb.12269.
MolluscaBase, 2015. http://www.molluscabase.org. Accessed 21 Nov 2015.

Neubauer, T. A., M. Harzhauser, E. Georgopoulou, A. Kroh \& O. Mandic, 2015. Tectonics, climate, and the rise and demise of continental aquatic species richness hotspots. Proceedings of the National Academy of Sciences of the United States of America 112: 11478-11483.

Normand, S., R. E. Ricklefs, F. Skov, J. Bladt, O. Tackenberg \& J.-C. Svenning, 2011. Postglacial migration supplements climate in determining plant species ranges in Europe. Proceedings of the Royal Society B: Biological Sciences 278: 3644-3653.

Oertli, B., D. Auderset Joye, E. Castella, R. Juge, D. Cambin \& J.-B. Lachavanne, 2002. Does size matter? The relationship between pond area and biodiversity. Biological Conservation 104: 59-70.

Økland, J., 1990. Lakes and Snails: Environment and Gastropoda in 1500 Norwegian Lakes, Ponds and Rivers. UBS/ Dr W. Backhuys, Oegstgeest.

Oksanen, J., F. G. Blanchet, R. Kindt, P. Legendre, P. R. Minchin, R. B. O'Hara, G. L. Simpson, P. Solymos, M. H. H. Stevens \& H. Wagner, 2015. vegan: Community Ecology Package. R package version 2.2-1. http://CRAN. R-project.org/package=vegan.

Quinn, G. P. \& M. J. Keough, 2002. Experimental design and data analysis for biologists. Cambridge University Press, Cambridge.

R Core Team, 2014. R: A Language and Environment for Statistical Computing. R Foundation for Statistical Computing, Vienna. http://www.R-project.org.

Radoman, P., 1985. Hydrobioidea, a Superfamily of Prosobranchia (Gastropoda), II. Origin, Zoogeography, Evolution in the Balkans and Asia Minor. Monographs Institute of Zoology 1, Beograd.

Rahbek, C. \& G. R. Graves, 2001. Multiscale assessment of patterns of avian species richness. Proceedings of the National Academy of Sciences of the United States of America 98: 4534-4539.

Rangel, T. F., J. A. F. Diniz-Filho \& L. M. Bini, 2010. SAM: a comprehensive application for Spatial Analysis in Macroecology. Ecography 33: 46-50.

Refseth, U. H., C. L. Nesbø, J. E. Stacy, L. A. Vøllestad, E. Fjeld \& K. S. Jakobsen, 1998. Genetic evidence for different migration routes of freshwater fish into Norway revealed by analysis of current perch (Perca fluviatilis) populations in Scandinavia. Molecular Ecology 7: 1015-1027.

Reyjol, Y., B. Hugueny, D. Pont, P. G. Bianco, U. Beier, N. Caiola, F. Casals, I. Cowx, A. Economou, T. Ferreira, G. Haidvogl, R. Noble, A. de Sostoa, T. Vigneron \& T. Virbickas, 2007. Patterns in species richness and endemism of European freshwater fish. Global Ecology and Biogeography 16: 65-75.

Reynolds, C., N. A. F. Miranda \& G. S. Cumming, 2015. The role of waterbirds in the dispersal of aquatic alien and invasive species. Diversity and Distributions 21: 744-754.

Salmi, M., 1963. On the subfossil Pediastrum algae and molluscs in the Late-Quaternary sediments of Finnish Lapland. Archivum Societatis Zoologicae Botanicae Fennicae Vanamo 18: 105-120. 
Sternai, P., F. Herman, J.-D. Champagnac, M. Fox, B. Salcher \& S. D. Willett, 2012. Pre-glacial topography of the European Alps. Geology 40: 1067-1070.

Strong, E. E., O. Gargominy, W. F. Ponder \& P. Bouchet, 2008. Global diversity of gastropods (Gastropoda; Mollusca) in freshwater. Hydrobiologia 595: 149-166.

Sturm, R., 2007. Freshwater molluscs in mountain lakes of the Eastern Alps (Austria): relationship between environmental variables and lake colonization. Journal of Limnology 66: $160-169$.

Svenning, J.-C., S. Normand \& F. Skov, 2008. Postglacial dispersal limitation of widespread forest plant species in nemoral Europe. Ecography 31: 316-326.

Svenning, J.-C., S. Normand \& F. Skov, 2009. Plio-Pleistocene climate change and geographic heterogeneity in plant diversity-environment relationships. Ecography 32: $13-21$.

Tollefsrud, M. M., R. Kissling, F. Gugerli, Ø. Johnsen, T. Skrøppa, R. Cheddadi, W. O. van der Knaap, M. Latałowa, R. Terhürne-Berson, T. Litt, T. Geburek, C. Brochmann \& C. Sperisen, 2008. Genetic consequences of glacial survival and postglacial colonization in Norway spruce: combined analysis of mitochondrial DNA and fossil pollen. Molecular Ecology 17: 4134-4150.

Tuomisto, H. \& K. Ruokolainen, 2006. Analyzing or explaining beta diversity? Understanding the targets of different methods of analysis. Ecology 87: 2697-2708.

Ulrich, W. \& S. Fattorini, 2013. Longitudinal gradients in the phylogenetic community structure of European Tenebrionidae (Coleoptera) do not coincide with the major routes of postglacial colonization. Ecography 36: 1106-1116.

van Leeuwen, C. H. A., G. van der Velde, B. van Lith \& M. Klaassen, 2012. Experimental quantification of long distance dispersal potential of aquatic snails in the gut of migratory birds. PLoS One 7: e32292. van Leeuwen, C. H. A., N. Huig, G. van der Velde, T. A. van Alen, C. A. M. Wagemaker, C. D. H. Sherman, M. Klaassen \& J. Figuerola, 2013. How did this snail get here? Several dispersal vectors inferred for an aquatic invasive species. Freshwater Biology 58: 88-99.

Vasari, Y., A. Vasari \& L. Koli, 1963. Purkuputaanlampi, a calcareous mud series from Kuusamo, North East Finland. Archivum Societatis Zoologicae Botanicae Fennicae Vanamo 18: 96-104.

Wagner, C. E., L. J. Harmon \& O. Seehausen, 2014a. Cichlid species-area relationships are shaped by adaptive radiations that scale with area. Ecology Letters 17: 583-592.

Wagner, B., T. Wilke, S. Krastel, G. Zanchetta, R. Sulpizio, K. Reicherter, M. J. Leng, A. Grazhdani, S. Trajanovski, A. Francke, K. Lindhorst, Z. Levkov, A. Cvetkoska, J. M. Reed, X. Zhang, J. H. Lacey, T. Wonik, H. Baumgarten \& H. Vogel, 2014b. The SCOPSCO drilling project recovers more than 1.2 million years of history from Lake Ohrid. Scientific Drilling 17: 19-29.

Walsh, C. \& R. Mac Nally, 2013. hier.part: Hierarchical Partitioning. R package version 1.0-4. http://CRAN.R-project. org/package=hier.part.

Welter-Schultes, F. W., 2012. European non-marine molluscs, a guide for species identification. Planet Poster Editions, Göttingen.

Wilke, T., C. Albrecht, V. V. Anistratenko, S. K. Sahin \& M. Z. Yildirim, 2007. Testing biogeographical hypotheses in space and time: faunal relationships of the putative ancient Lake Eğirdir in Asia Minor. Journal of Biogeography 34: 1807-1821.

Zhao, S., J. Fang, C. Peng, Z. Tang \& S. Piao, 2006. Patterns of fish species richness in China's lakes. Global Ecology and Biogeography 15: 386-394. 